\title{
Por um Ensino de Língua Portuguesa para além do Capital: Uma Análise Crítica da Base Nacional Comum Curricular sob o viés da Pedagogia Histórico-Crítica e da Educação Linguística
}

\author{
Pierre Silva Machado (FURG)* \\ https://orcid.org/0000-0001-6426-111X \\ Nycole Souza Prietsch (SMED)** \\ https://orcid.org/0000-0001-9195-3373 \\ Jane Helen Gomes de Lima (SMED)*** \\ https://orcid.org/0000-0001-6053-0669 \\ Sabatha Catoia Dias (GEPEL) ${ }^{* * * *}$ \\ https://orcid.org/0000-0002-2446-303X
}

\begin{abstract}
Resumo:
O seguinte estudo tem o objetivo de analisar a Base Nacional Comum Curricular no sentido de desvelar suas filiações teórico-filosóficas tanto no âmbito das teorias pedagógicas quanto no que se refere à abordagem do ensino de Língua Portuguesa. Para a análise, utilizam-se as orientações conceituais da Pedagogia Histórico-Crítica (SAVIANI, 2018) e da Educação Linguística (BRITTO, 2012), bem como a abordagem ontológica do método científico do Materialismo Histórico-Dialético (MARX, 2019). 0 exame documental re-
\end{abstract}

\footnotetext{
*estrando em Estudos da Linguagem pelo Programa de Pós-Graduação em Letras da Universidade Federal de Rio Grande (FURG); Graduação em Letras Português Inglês pela mesma universidade; Membro do Grupo de Estudos e Pesquisas em Educação Linguística (GEPEL - FURG/UFSC). Lattes: http://lattes.cnpq. br/6220159812402206. E-mail: pierresmachadorg@gmail.com

* Mestranda em Estudos da Linguagem pelo Programa de Pós-graduação na Universidade Federal de Rio Grande (FURG); Graduada em Letras Português Espanhol pela mesma universidade; Professora de Língua Portuguesa na Secretaria Municipal de Educação (SMED) em Rio Grande/RS. Lattes: http://lattes.cnpq. br/2220863281468053. E-mail: nyprietsch@gmail.com

*** Doutoranda em Inglês pelo Programa de Pós-Graduação em Inglês pela Universidade Federal de Santa Catarina (UFSC). Mestra em Educação Científica e Tecnológica pela mesma universidade; Professora de Inglês pela Secretaria Municipal de Educação (SMED) em Forquilhinha, SC. Lattes: http://lattes.cnpq. br/5418840317172089.E-mail: janehelenglima@gmail.com

**** Doutorado em Linguística Aplicada pelo Programa de Pós-Graduação em Linguística da Universidade Federal de Santa Catarina (UFSC); Professora Adjunta dos cursos de Letras da Universidade Federal de Rio Grande e do curso de Pós-Graduação em Letras da mesma universidade, Líder do Grupo de Estudos e Pesquisas em Educação Linguística (GEPEL). Lattes: http://lattes.cnpq.br/3389450097514723. E-mail: sabathadias@gmail.com.
} 
vela que a Base Nacional se alinha à chamada Pedagogia das Competências e orienta o trabalho educativo com educação linguística em conformidade com as determinações do modelo neoliberal vigente. Na contramão do documento oficial, e levando em conta os condicionantes objetivos da sociedade na sua relação com a educação, salienta-se a defesa de um Ensino de Língua Portuguesa para além do capital, ou seja, com vistas à formação humana integral e à emancipação.

Palavras-chave: Base Nacional Comum Curricular; Ensino de Língua Portuguesa; Pedagogia Histórico-Crítica; Educação Linguística; Materialismo Histórico-Dialético.

\section{Abstract:}

\section{For a Portuguese Language Teaching Beyond Capital: A Critical Analysis of the National Common Core Curriculum Based on the Historical-Critical Pedagogy and the Linguistic Education}

The following study aims at analysing the National Common Core Curriculum in order to exhibit its theoretical-philosophical affiliations both in the scope of the pedagogical theories and in relation to the Portuguese Language teaching approach. For the analysis, the conceptual orientations of the Historical-Critical Pedagogy (SAVIANI, 2018) and the Linguistic Education (BRITTO, 2012) are used, as well as the ontological framework of the scientific method from the Historical-Dialectical Materialism (MARX, 2019). The documental exam reveals that the National Common Core Curriculum is aligned to the so-called Competence-Based Pedagogy and guides the educational work with linguistic education in accordance with the determinations of the current neoliberal pattern. Contrary to the official document, and considering the objective conditionings of the society in its relationship with the education, it is highlighted the defense of a Portuguese Language Teaching beyond capital, that is, with a view on integral human formation and emancipation.

Keywords: Common Core Curriculum; Portuguese Teaching; Historical-Critical Pedagogy; Linguistic Education; Historical-Dialetical Materialism.

\section{Introdução}

0 processo educativo, como todo fenômeno social produto da atividade humana, é marcado por complexidade e caracterizado por determinações variadas que, em relação dialética, produzem contradições impulsionadoras de seu desenvolvimento. Conforme afirma Saviani (2016, p. 65), “[...] a observação imediata [do processo educativo] nos coloca diante de um universo empírico bastante heterogêneo seja quanto às formas de organização e efetivação, seja quanto às representações que dele fazem seus agentes".

Nos mesmos moldes, apresenta-se o trabalho educativo com Língua Portuguesa (LP) nas instituições formativas brasileiras, o qual, nos últimos anos, após consolidação 
de teorias de cunho sociologista e/ou histórico-cultural no cenário nacional, tem sido levado a termo a partir de ações alinhadas a perspectivas que ora tendem a definir as práticas de uso da língua como centro do ensino, ora concentram seus esforços nas regularidades dos gêneros do discurso. Importante explicar que tais enfoques no trato com a língua, muitas vezes, consubstanciam-se com uma abordagem linguística estrutural, insistentemente presente nos bancos escolares, tal qual verificam diversos estudos da área, a exemplo de Catoia Dias (2016) e Tomazoni (2016).

Com a implementação da Base Nacional Comum Curricular (BNCC), aparentemente, atenta-se para a superação da visão estrutural de língua, visto que "assume-se [...] a perspectiva enunciativo-discursiva de linguagem" (BRASIL, 2018, p. 67), assim como em outro documento oficial balizador do ensino no país, os Parâmetros Curriculares Nacionais (BRASIL, 1998). Enquanto documentos governamentais, elaborados em cronotopias específicas, por agentes determinados, expressando, portanto, axiologias vinculadas a visões de mundo e de educação próprias ${ }^{1}$, consistem em produtos históricos cujo conteúdo, tomado como uma totalidade

1 Explicitam Marsiglia et al. (2017) que a Base Nacional Comum Curricular foi uma exigência da Constituição Federal de 1988, dos organismos internacionais, da Lei de Diretrizes e Bases da Educação Nacional (BRASIL, 2012) de 1996 e de três das metas do Plano Nacional de Educação (PNE) 2014-2024. Aparelhos privados empresariais como Fundação Roberto Marinho, Instituto Ayrton Senna, CENPEC, Fundação Itaú Social, Instituto Unibanco, Fundação Lemann, Instituto Natura, além do organismo Todos pela Educação, são alguns dos grupos hegemônicos que se articularam no chamado "Movimento pela Base Nacional Comum", imprimindo, dessa forma, uma lógica mercadológica aos chamados conteúdos mínimos previstos para a Educação Básica brasileira, com vistas a uma formação humana unilateral. composta por contradições em movimento dialético, premem por desnudamentos por parte daqueles envolvidos na/com a educação e ocupados com uma formação humana integral, promovedora de sujeitos críticos e conscientes no que diz respeito a sua relação com as objetivações genérico-humanas alcançadas pela história da sociedade.

Encerrados nessa compreensão, no presente capítulo, temos o objetivo de analisar a BNCC no sentido de desvelar suas filiações teórico-filosóficas no que tange à(s) teoria(s) pedagógica(s) e à concepção de ensino de LP, problematizando-as, especialmente no que compete ao trato do conhecimento e ao uso de "competências" nas propostas pedagógicas para o componente curricular de LP. Além disso, propomos uma reflexão cujo foco seja o ensino de português que considere a relação dialética entre sociedade e educação e em que a língua seja concebida como fenômeno histórico complexo e objeto social.

Para tanto, lançando mão dos princípios do Materialismo Histórico-Dialético (MHD), a apreciação do documento se fará à luz das categorias teórico-metodológicas desta filosofia (NETTO, 2011). Ainda, utilizaremos os pressupostos teóricos da Pedagogia Histórico-Crítica (SAVIANI, 2018) e da Educação Linguística (BRITTO, 2012) a fim de refletir a relação da BNCC com a ordem político-social vigente, a educação, as teorias educacionais e pedagógicas, a finalidade da escola, as responsabilidades do professor e do aluno, o conhecimento e a educação em linguagem.

Quanto às resoluções oriundas deste trabalho, vale antecipar que a BNCC se associa à Pedagogia das Competências e orienta um ensino de LP em conformidade com as determinações do sistema capitalista. A partir dessas constatações, propomos uma discussão sobre trabalho com linguagem pauta- 
do em uma educação para além do capital (MÉSZÁROS, 2008).

\section{Por um Ensino de Língua Portuguesa para além do Capital}

Diversos estudos sobre o ensino de LP denotam a prevalência do viés sistêmico da língua, em que o trabalho educativo se foca em gramática normativa em perspectiva prescritiva e metalinguística (CATOIA DIAS, 2016; TOMAZONI, 2016). No entanto, a Linguística Aplicada (LA), por mais de 40 anos, tem realizado pesquisas que pleiteiam a necessidade de considerar o fenômeno linguístico como objeto social.

Sendo assim, inúmeras abordagens e metodologias alternativas foram desenvolvidas no esforço de superar o caráter estrutural da educação em linguagem, promover maior engajamento dos estudantes e obter resultados mais satisfatórios no ensino e na aprendizagem de LP. Apesar disso, para compreender as razões para o trabalho com língua na direção da língua como sistema abstrato, é necessário aprofundar o debate sobre as questões relacionadas à sociedade, à organização político-social, ao conhecimento, à educação, à escola em relação dialética com a sociedade, às teorias educacionais e pedagógicas e ao ensino em linguagem.

Para tanto, a reflexão sobre a problemática do trabalho com linguagem será dividida em três partes: Sociedade, Conhecimento, Educação e Pedagogia(s), Princípios da Pedagogia Histórico-Crítica e Fundamentos da Educação Linguística.

\subsection{Sociedade, Conhecimento, Edu- cação e Pedagogia(s)}

Para Marx (2019), o trabalho, categoria central do MHD, é compreendido como atividade humana vital, em que os homens transformam a natureza e a si mesmos, e é fundamental para a produção da base material e para a reprodução da sociedade. Ontologicamente, o trabalho promove humanização; na organização social atual, percebe-se "o desvirtuamento das características do próprio trabalho" (MARTINS, 2015, p. 33), uma vez que se tornou desumanizado, ou seja, alienado. $\mathrm{Na}$ ordem social regida pelo capital, "a transformação da natureza é realizada por uma parte dos trabalhadores e a riqueza resultante é deles expropriada pela classe dominante" (LESSA; TONET, 2011, p. 93).

Na modernidade, vimos a emergência da divisão do trabalho e, com ela, o surgimento da sociedade de classes ${ }^{2}$ : burguesia e proletariado. Em resposta à exploração dos trabalhadores pelos burgueses, de acordo com a teoria marxista, o proletariado precisa tomar consciência de um instrumento (utilizado intrinsicamente pela burguesia devido à apropriação dos meios de produção) para transformação de sua realidade social: a luta de classes. A partir da reflexão sobre a sociedade, alvitra-se relacioná-la dialeticamente com o conhecimento e a educação.

Inicialmente, identifica-se o conhecimento como outra arena cuja luta de classes é percebida e "o domínio do conhecimento é uma das armas que a classe dominante emprega para neutralizar as ações potencialmente revolucionárias" (SAVIANI; DUARTE, 2015, p. 8-9). Por conseguinte, admitindo o conhecimento como ferramenta de dominação, a escola deve reconhecer tal desigualdade e assumir sua finalidade essencial na sociedade burguesa: espaço da socialização e da

2 Temos ciência de que, hoje, com o desenvolvimento social, houve mudanças estruturais que acarretaram o surgimento de novas e outras classes; no entanto, para fins didáticos, utilizaremos as categorias presentes no pensamento marxiano. 
Por um Ensino de Língua Portuguesa para além do Capital: Uma Análise Crítica da Base Nacional Comum Curricular sob o viés da Pedagogia Histórico-Crítica e da Educação Linguística

\section{apropriação do conhecimento científico}

sistematizado e acumulado historicamente pela humanidade (SAVIANI, 2013; SAVIANI; DUARTE, 2015). Para que isso se materialize, é basilar que os docentes se apropriem dos mais diversos conhecimentos relativos à práxis $^{3}$ do seu trabalho educativo.

No entanto, presencia-se a desvirtuação do propósito da escola e, em termos de ação pedagógica, experienciam-se, ainda hoje, os efeitos dos projetos político-pedagógicos de cunho neoliberal, à serviço do mercado e suas demandas. Sob a égide da superação do ensino tradicional, algumas perspectivas pedagógicas ocupam os espaços escolares e não respondem às problemáticas históricas da educação brasileira. Com o intuito de entender essa situação, esboçaremos uma sistematização das teorias educacionais e pedagógicas.

Sabemos que toda ação pedagógica desenvolvida em sala de aula está ancorada em conceitos e conhecimentos de teorias (modelos cultural-cognitivos e didático-pedagógicos ${ }^{4}$ ) que, ao serem selecionadas como base teórica do trabalho educativo, exteriorizam a visão de mundo, de homem e de sociedade dos docentes. Destarte, no contexto

3 Para Tonet (2013), a práxis é uma categoria do pensamento marxiano, a qual possibilita a mediação dos dois momentos constitutivos de uma unidade indissolúvel: subjetividade e objetividade. Para além disso, é caracterizada por ser voltada para determinados fins, por projetar-se nas ideias e por ser objetiva (concreta). No sentido da educação, concebemos a práxis educativa como ação docente teórico-prática, em que a teoria orienta a prática e, dialeticamente, é orientada por essa. Desse modo, a teoria se modifica por conta da experiência prática que, por sua vez, modifica-se constantemente com a teoria.

4 Segundo Saviani (2009), existem dois modelos de formação docente: aqueles que privilegiam as teorias educacionais e pedagógicas (didático -pedagógicos) e os que preconizam as teorias da área de conhecimento específico (cultural-cognitivos). do debate educacional brasileiro, nota-se a presença quase hegemônica de teorias educacionais e pedagógicas que desconsideraram os determinantes socioeconômicos que limitam o desenvolvimento e desviam a finalidade da escola.

Nesse sentido, Saviani $(2008 ; 2018)$ propõe uma sistematização das teorias em que o critério de criticidade tem relação com a “percepção dos condicionantes objetivos [da escola em relação aos determinantes sociais]" (SAVIANI, 2018, p. 5). Assim, o autor classifica as teorias educacionais e pedagógicas em dois grupos: as teorias não críticas (ou hegemônicas) e as teorias crítico-reprodutivistas (ou contra-hegemônicas) ${ }^{5}$.

Dentre as teorias não críticas, encontram-se aquelas que "encaram a educação como autônoma e buscam compreendê-la a partir dela mesma" (SAVIANI, 2018, p. 5). No grupo das teorias crítico-reprodutivistas, estão incluídas aquelas que tornam relevantes os condicionantes objetivos (estrutura socioeconômica) determinantes da escola, embora entendam que ela reproduza a sociedade e, portanto, não acreditem que a escola tenha a potencialidade da transformação da realidade.

Ainda, no bojo das teorias pedagógicas, Duarte (2011) aponta as Pedagogias do "Aprender a Aprender". Nessas perspectivas, percebem-se quatro traços orientadores em comum no trabalho educativo: a pesquisa como princípio educativo, a primazia do método de construção do conhecimento

5 No que se refere às teorias não críticas, citamos a Pedagogia Tradicional, baseada em Herbart e Bacon, a Pedagogia Nova, de Dewey, e a Pedagogia Tecnicista, com expoente em Delors. Com relação às crítico-reprodutivistas, destacamos a Teoria do Sistema de Ensino como Violência Simbólica, de Bourdieu e Passeron, a Teoria da Escola como Aparelho Ideológico do Estado (AIE), de Althusser, e a Teoria da Escola Dualista, de Baudelot e Establet. 
(em comparação ao conhecimento produzido socialmente pela humanidade), a atividade educativa voltada para os interesses e as necessidades do aluno e a concepção educacional voltada para a formação adaptativa dos indivíduos (DUARTE, 2011).

Na concepção dessas pedagogias modernas, releva-se "o conflito criado na sociedade burguesa entre as tendências para o desenvolvimento do indivíduo e as condições sociais existentes" (SUCHODOLSKI, 2000, p. 99-100), com a camuflagem das incoerências de suas próprias filosofias. Para além disso, há um equívoco a respeito do conceito de prática social, pois equiparam prática cotidiana e prática social. Ao contrário, a prática social humana não pode ser reduzida à cotidianidade, visto que "a prática cotidiana é apenas a forma fenomênica da totalidade da prática social" (DUARTE, 2010, p. 44).

Para que a escola se torne um espaço destinado ao saber escolar sistematizado, é coerente que se invista em uma pedagogia que seja crítica sem ser reprodutivista, ou seja, uma teoria "formulada do ponto de vista dos interesses dos dominados" (SAVIANI, 2018, p. 25), que supere por incorporação as outras teorias pedagógicas e que, através da práxis, enfrente o problema da marginalização. Logo,

do ponto de vista prático, trata-se de retomar vigorosamente a luta contra [...] o rebaixamento do ensino das camadas populares. Lutar contra a marginalidade por meio da escola significa engajar-se no esforço para garantir aos trabalhadores um ensino da melhor qualidade possível nas condições históricas atuais. 0 papel de uma teoria crítica da educação é dar substância concreta a essa bandeira de luta de modo a evitar que ela seja apropriada e articulada com os interesses dominantes. (SAVIANI, 2018, p. 26)

A seguir, apresentamos os constructos teórico-filosóficos que orientam a Pedago- gia Histórico-Crítica, um caminho possível na busca por uma escola preocupada com as desigualdades relacionadas à sociedade de classes.

\subsection{Princípios da Pedagogia Histórico-Crítica}

Em meados dos anos 1980, foi elaborada uma teoria educacional e pedagógica no sentido de superar por incorporação as demais teorias existentes, estabelecer vínculo com a luta socialista e a transformação social e admitir o caráter revolucionário da educação dentro dos limites do capital: a Pedagogia Histórico-Crítica (PHC) (SAVIANI, 2018). No cerne dessa teoria, concede-se à escola o status de instituição formal dedicada ao trabalho educativo, que é "o ato de produzir, direta e intencionalmente, em cada indivíduo singular, a humanidade que é produzida histórica e coletivamente pelo conjunto dos homens" (SAVIANI, 2013, p. 13).

Admitindo a escola como espaço de socialização do conhecimento científico, propõe-se, na perspectiva histórico-crítica, a formação humana integral com vistas à emancipação ${ }^{6}$. No escopo da PHC, ainda, cabe tratar do lugar do conhecimento e das responsabilidades do professor e do aluno

6 A formação humana integral, objetivo central para o trabalho educativo, faz referência ao conceito marxista de omnilateralidade, que se relaciona ao desenvolvimento das múltiplas potencialidades dos sujeitos. Destaca-se, assim, o trabalho enquanto princípio educativo, em oposição à unilateralidade do homem na sociedade capitalista, gerada a partir da separação entre a atividade material e a atividade intelectual. No que concerne à emancipação, Lessa e Tonet (2011) expõem que a teoria marxista indica que o homem tem a potencialidade de romper com a submissão ao capital se obtiver o conhecimento adequado da realidade para a escolha dos objetivos que respondam às necessidades humanas da classe proletária, emancipando-se através da revolução. 
nos processos de ensino e aprendizagem. Para a PHC, diferentemente da Pedagogia Tradicional (cuja centralidade é no professor) e da Pedagogia Nova (cuja centralidade é no aluno), o trabalho educativo está centralizado no conhecimento, visto que esse é distribuído desigualmente na sociedade de classes. Por isso, a PHC defende que os filhos dos trabalhadores tenham acesso ao patrimônio cultural historicamente desenvolvido.

Quanto às atribuições do professor e do aluno, a PHC objetiva que ambos sejam agentes da transformação social. No entanto, Saviani (2018) aponta que, quanto à compreensão da prática social ${ }^{7}$, o aluno tem um olhar sincrético e o professor, sintético. Para a PHC,

a compreensão do professor é sintética porque implica uma certa articulação dos conhecimentos e das experiências que detém relativamente à prática social. [...] A compreensão dos alunos é sincrética uma vez que, por mais conhecimentos e experiências que detenham, sua própria condição de aluno implica uma impossibilidade [inicialmente] de articulação da experiência pedagógica na prática social de que participam. (SAVIANI, 2018, p. 57)

Como a PHC compreende os processos de ensino e de aprendizagem de forma distinta, é importante elencar que o professor tem como atividade principal o ensino, ao passo que o aluno tem como atividade principal a aprendizagem. Isso não quer dizer que o aluno haja passivamente, pois ele é ativo durante o processo educativo. $\mathrm{Na}$ abordagem teórico-metodológica da PHC, são considerados dois elementos distintos: a cultura popular e a cultura erudita.

Para a PHC, os interesses do aluno de-

7 Para Saviani (2018), a prática social diz respeito à atividade humana na realidade social e é o ponto de partida e chegada do trabalho educativo. vem ser levados em conta, bem como os conhecimentos que ele já traz consigo para a escola. Entretanto, esses interesses e conhecimentos, enquanto cultura popular, devem ser ponto de partida, uma vez que os conhecimentos científicos e a cultura erudita são saberes aos quais os alunos são expostos desigualmente na sociedade burguesa e, por isso, devem ser o ponto de chegada. Ao longo do trabalho educativo, o professor deve utilizar momentos teórico-metodológicos ${ }^{8}$ e, em suma, deve conduzir o aluno do senso comum à consciência crítica sobre as práticas sociais vivenciadas na sociedade por meio da apropriação dos saberes escolares sistematizados.

Na próxima seção, apresentamos e discutimos os fundamentos da Educação Linguística conforme as orientações de Britto (2012) e debatemos sobre a importância do ensino de leitura e da escrita na sala de aula de LP.

\subsection{Fundamentos da Educação Linguística}

Compreendida a desigualdade de acesso ao conhecimento, voltemo-nos, de fato, para o ensino de LP, objeto de interesse deste estudo. Para discutir a educação em linguagem, retornamos à problemática apresentada na introdução deste capítulo: a prevalência da perspectiva sistêmica de língua no ensino de LP. De acordo com Britto,

os modelos de reformulação do ensino de

8 Em termos teórico-metodológicos, na PHC, Savini (2018) expõe cinco momentos: a prática social (inicial, sincrética), a problematização (detecção de questões no âmbito da prática social), a instrumentalização (apropriação das ferramentas culturais necessárias à luta social), a catarse (expressão elaborada da nova forma de compreensão da prática social e incorporação dos instrumentos culturais, transformados em elementos ativos de transformação social) e a prática social (diferente da inicial, nova, sintética). 
Língua Portuguesa consequentes do avanço da Linguística e das renovadas teorias de educação e de aprendizagem não vingaram efetivamente porque, quando incorporadas aos fazeres escolares, tais teorias foram absorvidas como se o problema fosse de ordem metodológica [...]. Ademais, mesmo quando se consideram os referenciais da Linguística contemporânea, a formação docente mantém-se presa ao dilema normativo, de modo que a questão continua sendo a de como ensinar o certo. (BRITTO, 2012, p. 93)

Como vimos, apesar dos progressos advindos dos estudos linguísticos, os professores aparentam sobrepujar, nos bancos escolares da Educação Básica, práticas pedagógicas balizadas pela correção de desvios do uso da língua. Britto (2007) afirma que a educação em linguagem tem desconsiderado um aspecto central, a saber, o conhecimento, e limita-se à demonstração do "correto" ou localiza-se na perspectiva dos usos funcionais cotidianos, sempre voltados para a satisfação das demandas do sistema capitalista.

Aliás, é mister evitar concepções dicotômicas e padrões qualitativos e descritivos dos usos da língua, com o emprego de termos tais como padrão e não-padrão ou, ain$\mathrm{da}$, adequado e inadequado. Isso porque as diferentes formas de apreensão do fenômeno linguístico são legítimas e resultados da "política e dos focos de interesse que se manifestam nas formas como se realiza a luta pelo poder" (BRITTO, 2007, p. 24). Além de tudo, o preconceito linguístico surge quando determinadas formas são reconhecidas e certos padrões de (in)cultura são reproduzidos continuamente e, de modo sistemático, ameaçam a integridade social dos dominados através de paradigmas regulatórios e corretivos.

Destarte, proporemos um ensino de LP em que a finalidade da educação escolar seja considerada, a saber: a expansão dos conhecimentos tácitos (cotidianos) dos alunos e o rompimento com o senso comum por meio do "desenvolvimento intelectual e social dos alunos" (BRITTO, 2012, p. 83), evitando-se imediatismos e pragmatismos. Para isso, a língua deve ser concebida como totalidade constituída na história humana e constitutiva dos sujeitos, de relação e de intervenção no mundo e fenômeno histórico que se realiza e se produz em função do trabalho humano.

Delineado o fenômeno linguístico, lançase um olhar sob uma perspectiva de ensino engajada com a língua como objeto social e relacionada aos condicionantes objetivos da escola na sua ligação íntima com a realidade social. Sendo assim, recorremos à Educação Linguística (EL), definida como

[...] ação pedagógica que leve o estudante a perceber a língua e a linguagem como fenômenos históricos complexos, a compreender seu funcionamento, usos e formas, bem como a saber usá-la com propriedade nas modalidades oral e escrita, em especial para estudar e aprender a viver sua subjetividade. (BRITTO, 2012, p. 84)

Nesse viés, os professores de LP devem privilegiar o conhecimento científico, artístico e filosófico via leitura, escrita e seus discursos, pois a sociedade é centrada no grafocentrismo. Além disso, a aquisição da compreensão leitora e o domínio da produção textual, distribuídos de forma desigual na sociedade burguesa (de classes), tornam-se condição sine qua non para a inserção social. Deve-se, portanto, ter ciência do

[...] vínculo estrito entre escrita e as formas de poder e de apropriação dos bens simbólicos produzidos na própria cultura escrita. E isso não é de se estranhar quando se considera uma ordem social em que a apropriação desigual da produção é essencial. (BRITT0, 2007, p. 25) 
Ainda, na sala de aula de LP, o docente também deve dispor de um repertório de gêneros discursivos (BAKHTIN, 2000) e selecionar textos com os quais os alunos possam ter contato com a língua e com as diversas temáticas que demandam transformação social no sentido de ampliar o conhecimento sobre o fenômeno linguístico e sobre o mundo (BRITTO, 2012). Ancorado nos pressupostos teóricos da PHC, o docente deve partir de gêneros do discurso com os quais o estudante já é familiarizado e, gradualmente, oportunizar a leitura daqueles com os quais teve pouco ou nenhum contato.

Por fim, é essencial que haja o trabalho com os diferentes objetos culturais na sala de aula de LP, especialmente a literatura. A leitura de textos literários, mesmo quando tomados como objeto de ensino, possibilita o contato com uma forma de arte não manifesta cotidianamente na realidade dos discentes. Não se pode presumir que os discentes já tenham manuseado textos clássicos, portanto é necessário ir além de bestsellers e outros gêneros literários comumente disseminados entre os educandos. Nesse sentido, o docente deve oportunizar o contato com o cânone literário, em virtude da inserção social dos alunos na cultura erudita e no mundo das experiências culturais e intelectuais.

Todavia, muitos professores podem ser atraídos pelas armadilhas da Pedagogia do Gostoso (BRITTO, 2012), cuja prática resulta em atender aos interesses imediatos dos alunos, banalizar o relativismo e facilitar a reprodução de uma educação ancorada no senso comum. Na contramão da Pedagogia do Gostoso, os professores devem estar cientes de que aprendizagem não pode ser sinônimo de lazer, pois é oriunda de trabalho (educativo). Na próxima seção, faremos uma análise crítica das orientações pedagó- gicas contidas na BNCC no tocante à disciplina de LP.

\section{Conformação ou superação: uma análise crítica da BNCC}

Com base na discussão teórica proposta, a BNCC foi analisada criticamente com o propósito de desvelar suas filiações teórico-filosóficas tanto no âmbito das teorias pedagógicas quanto no que se refere à abordagem do ensino de Língua Portuguesa. Para que isso fosse possível, delimitou-se o método do MHD. Na perspectiva marxista, concebemos, assim como Tonet (2013), que não há método a priori em uma abordagem ontológica, pois o que se pretende é ir para além da aparência fenomênica do objeto de estudo9.

Ainda assim, a teoria social marxista engendra categorias teórico-metodológicas - totalidade, mediação e contradição - para que se compreenda a essência (estrutura e dinâmica) e se desvele a realidade concreta pensada do objeto. Conforme Netto (2011), tais categorias devem ser indissociavelmente manipuladas, visto que estão em relação dialética. Portanto, um objeto de estudo é concebido como totalidade macroscópica, inclusiva e de máxima complexidade, se estruturando e se articulando com outras totalidades menos complexas. Em sua dinamicidade, a totalidade macroscópica se movimenta como resultado do caráter

9 Para tanto, inicia-se a partir da realidade concreta imediata (caótica), por meio de dados e, através da análise, faz-se a abstração de determinados elementos. Posteriormente, obtêm-se as determinações simples e, em seguida, realiza-se o movimento inverso. Ao fazer isso, busca-se não mais uma representação caótica do real e do concreto, mas sim "uma rica totalidade de determinações e relações diversas" (NETTO, 2011, p. 43). Como visto, para a teoria marxista, o método se constitui na e pela análise do objeto estudado. 
contraditório das totalidades constitutivas, permitindo-lhe a sua transformação. Os processos de cada uma dessas totalidades constitutivas apreendidas na sua diversidade se relacionam entre si e com a totalidade macroscópica mediados pelos seus diferentes níveis de complexidade e suas estruturas peculiares.

No escopo da presente pesquisa, o objeto central é o ensino de LP, totalidade macroscópica de máxima complexidade. Essa engloba as seguintes totalidades constitutivas: a(s) teoria(s) pedagógica(s), a(s) teoria(s) linguística(s), a formação docente em Letras e a BNCC, regulada, implementada e, em relação ao contexto histórico da constituição do documento, imposta pelo Estado. No recorte da pesquisa, consideram-se todas as totalidades constitutivas, exceto a formação docente, a ser investigada. Para o estudo, a categoria teórico-metodológica central emergente da análise do objeto foi a contradição.

A respeito do exame do documento, preliminarmente, identificou-se sua filiação à Pedagogia das Competências (PC). No abajur das pedagogias do "Aprender a Aprender", tal concepção se organiza em torno do ensino centrado "na produção de competências verificáveis em situações e tarefas específicas" (RAMOS, 2006, p. 221), em convergência com as demandas da realidade social atual e do mercado de trabalho. Em contraste com o que pode aparentar, competência remodela o termo 'saber fazer' e se pauta "no critério de lucratividade e da sociabilidade adaptativa" (MARTINS, 2010, p. 19). No entanto, para Ramos (2006), os saberes escolares dos quais a escola deveria se ocupar foram embebidos de sentido prático e cotidiano quando apropriados pela PC. Nessa direção, a escola se torna um espaço voltado à qualificação para atuação profissional. Para a leitura da BNCC, quatro eixos analíticos serão destacados: princípio educativo, foco do trabalho educativo, conhecimento preconizado e vínculo com a ordem político-social.

No que tange ao princípio educativo, destacam-se os seguintes excertos para análise: "campo das práticas de estudo e pesquisa" (BRASIL, 2018, p. 84); "a perspectiva investigativa", "a pesquisa e a produção colaborativa" como "modo privilegiado de tratar os conhecimentos" (ibidem, p. 486); "para construir conhecimentos (inclusive escolares)" (ibidem, p. 87). Por meio deles, é possível indicar que a BNCC emprega a pesquisa como princípio educativo, visto que privilegia a pesquisa no trato com os conhecimentos. Acerca do foco no trabalho educativo, ao alocar-se diante dos interesses e das necessidades do alunado, o documento centraliza o aluno, que deve buscar e construir conhecimento. Sob o escrutínio da autonomia, conforme Duarte (2011), a PC valora hierarquicamente a aprendizagem por si mesmo e, ainda, ignora a iniciativa do professor no que diz respeito ao ensino, atribuindo-lhe a função de facilitador. Logo, perde-se aquilo que a PHC e a EL preconizam: o foco no conhecimento (SAVIANI, 2018) e a educação em linguagem para além do imediato e pragmático (BRITTO, 2012).

Quanto ao conhecimento preconizado, sublinham-se os trechos a seguir: "textos multissemióticos [disponibilizados] nas redes sociais" (BRASIL, 2018, p. 68); "produção de memes" (ibidem, p. 69); atreladas "[práticas de linguagem atreladas] às situações da vida social e [...] em contextos significativos para os estudantes" (ibidem, p. 84). Ao discorrer sobre as práticas de linguagens contemporâneas, fica evidente a prerrogativa do conhecimento cotidiano, em virtude de que é orientado o trabalho com gêneros 
com os quais os estudantes já dominam e são familiarizados. Fica evidente que a BNCC, na senda dos avanços tecnológicos, distancia-se do propósito de escola como espaço de socialização do conhecimento científico (SAVIANI, 2018) e que a leitura e a escrita não rompem com o senso comum, conforme a EL proposta por Britto (2012).

Sobre o vínculo com a ordem políticosocial, frisam-se as seguintes orientações da BNCC: "mundo do trabalho" (BRASIL, 2018, p. 478); "empreendedorismo" (ibidem, p. 479); "formação integral" (ibidem, p. 481); "ferramentas para a transformação social" (ibidem, p. 506). Em primeiro lugar, enfatiza-se a natureza contraditória das terminologias analisadas, pois tanto a PC (voltada para a adaptação dos indivíduos às novas demandas do capital) não se pauta na formação humana integral como o enfoque exacerbado no mercado de trabalho ressalta a essência alienadora da BNCC. Em consonância com isso, a definição de trabalho do documento, "ato humano de transformar a natureza [...] e de (re)produção da vida material" (ibidem, p. 505) não condiz com as práticas pedagógicas alienadoras nele orientadas. Também, a presença dos termos formação integral e transformação social são higienizadas, dado que a formação sugerida não parece ser, de fato, humana e, ao desconfigurar as iniciativas dos alunos e dos professores na relação com a aprendizagem e o ensino, limitam a caracterização desses como agentes da transformação social (SAVIANI, 2018). Na relação com o sistema vigente, portanto, o documento revela a sua conformidade com o sistema capitalista na medida em que favorece, na contramão do que Britto (2012) preconiza, as demandas do mercado e concebe trabalho (alienado) na sua forma fragmentada (atividade intelectual e material).

\section{Considerações Finais}

No presente estudo, abordaram-se questões basilares da relação entre sociedade e escola. Ademais, apresentaram-se os princípios da PHC e apontaram-se os fundamentos da EL. Logo após, realizou-se a análise crítica da BNCC por meio das categorias teóricometodológicas do MHD e dos constructos teóricos da PHC e da EL.

Durante a análise da BNCC, revelaram-se os seguintes aspectos sobre o ensino de LP: vínculo com a $\mathrm{PC}$, pesquisa como princípio educativo, predomínio do conhecimento cotidiano, enfoque no aluno no trabalho educativo e conformidade com as determinações do sistema capitalista. Em síntese, concluise que a BNCC não promove um ensino de LP com vistas à formação humana integral e à emancipação. Com o (re)conhecimento da concepção teórico-filosófica imbuída na BNCC, é imprescindível ampliar o repertório de discussões críticas ao documento, orientador do trabalho dos professores de LP e balizador das práticas pedagógicas em linguagem.

\section{Referências}

BAKHTIN, M. Estética da criação verbal. $3^{3}$ ed. São Paulo: Martins Fontes, 2000.

BRASIL. Ministério da Educação. Secretaria de Educação Fundamental. Parâmetros Curriculares Nacionais: terceiro e quarto ciclos do ensino fundamental: introdução aos parâmetros curriculares nacionais. Brasília, DF: MEC/SEF, 1998.

BRASIL. Lei de Diretrizes e Bases da Educação Nacional: lei no 9.394, de 20 de dezembro de 1996, que estabelece as diretrizes e bases da educação nacional. - 7. ed. - Brasília: Câmara dos Deputados, Edições Câmara, 2012.

BRASIL. Ministério da Educação. Base Nacional Comum Curricular. Brasília, 2018.

BRITTO, L. P. L. Escola, Ensino de Língua, Letramento e Conhecimento. Calidoscópio, v. 5, n. 1, 
p. 24-30, jan/abr 2007.

Inquietudes e Desacordos: a Leitura além do Óbvio. Campinas, SP: Mercado de Letras, 2012.

CATOIA DIAS, S. Entre Ecos e Travessias: um Olhar para o Ato de Ler no Processo de Educação em Linguagem na Esfera Escolar. 2016. Tese (Doutorado em Linguística) - Programa de Pósgraduação em Linguística, Universidade Federal de Santa Catarina. Florianópolis, 2016.

DUARTE, N. O Debate Contemporâneo das Teorias Pedagógicas. In: MARTINS, L. M.; DUARTE, N. (Orgs.). Formação de Professores: Limites Contemporâneos e Alternativas Necessárias. São Paulo: Cultura Acadêmica, 2010, p. 33-50.

Vigotski e o "Aprender a Aprender": Crítica às Apropriações Neoliberais e PósModernas da Teoria Vigotskiana. 5. ed. Campinas: Autores Associados, 2011.

LESSA, S.; TONET, I. Introdução à Filosofia de Marx. São Paulo: Expressão Popular, 2011.

MARSIGLIA, A. C. G. et al. A Base Nacional Comum Curricular: um Novo Episódio de Esvaziamento da Escola no Brasil. Germinal: Marxismo e Educação em Debate, Salvador, v. 9, n. 1, p. 107-121, abr. 2017.

MARTINS, L. M. O Legado do Século XX para a Formação de Professores. In: MARTINS, L. M.; DUARTE, N. (Orgs.). Formação de Professores: Limites Contemporâneos e Alternativas Necessárias. São Paulo: Cultura Acadêmica, 2010, p. 13-31.

A Formação da Personalidade do Professor: um Enfoque Vigotskiano. 2. ed. Campinas: Autores Associados, 2015.

MARX, K. 0 Capital: Crítica da Economia Política, v. I. 36. ed. Trad. Reginaldo Sant'Anna. Rio de Janeiro: Civilização Brasileira, 2019.

MARX, K; ENGELS, F. Manifesto do Partido Comunista. Porto Alegre: L\&PM Pocket, 2009.
MÉSZÁROS, I. A Educação para além do Capital. São Paulo: Boitempo, 2008.

NETTO, J. P. Introdução ao Estudo do Método de Marx. São Paulo: Editora Expressão Popular, 2011.

RAMOS, M. N. A Pedagogia das Competências: Autonomia ou Adaptação. 3. ed. São Paulo: Cortez, 2006.

SAVIANI, D. Teorias Pedagógicas Contra-Hegemônicas no Brasil. Revista do Centro de Educação e Letras da UNIOESTE - Campus Foz do Iguaçu, v. 10, n. 2, p. 11-28, 2008.

Pedagogia Histórico-Crítica: Primeiras Aproximações. 11. ed. Campinas: Autores Associados, 2013.

. Educação Escolar, Currículo e Sociedade: o Problema da Base Nacional Comum Curricular. Movimento - Revista de Educação, ano 3, n. 4, p. 54-84, 2016.

. Escola e Democracia. 43. ed. Campinas: Autores Associados, 2018.

SAVIANI, D.; DUARTE, N. (Org.). Pedagogia Histórico-Crítica e Luta de Classes na Educação Escolar. Campinas, SP: Autores Associados, 2015.

SUCHODOLSKI, B. A Pedagogia e as Grandes Correntes Filosóficas: a Pedagogia da Essência e a Pedagogia da Existência. Lisboa: Livros Horizonte, 2000.

TOMAZONI, E. o Ato de Escrever em Encontros na Escola. 2016. Tese (Doutorado em Linguística) - Programa de Pós-graduação em Linguística, Universidade Federal de Santa Catarina, Florianópolis, 2016.

TONET, I. Método Científico: uma Abordagem Ontológica. São Paulo: Instituto Lukács, 2013.

Recebido em: 16/04/2021 Aprovado em: 10/08/2021 